\title{
Process Optimization for Ethyl Ester Production in Fixed Bed Reactor Using Calcium Oxide Impregnated Palm Shell Activated Carbon (CaO/PSAC)
}

\author{
A. Buasri*, B. Ksapabutr, M. Panapoy and N. Chaiyut \\ Department of Materials Science and Engineering, Faculty of Engineering and Industrial Technology, \\ Silpakorn University, Nakhon Pathom THAILAND \\ National Center of Excellence for Petroleum, Petrochemicals and Advanced Materials, \\ Chulalongkorn University, Bangkok THAILAND
}

\section{Article history:}

Received July 20, 2012 Received in revised form August 14, 2012 Accepted September 26, 2012 Available online

\begin{abstract}
The continuous production of ethyl ester was studied by using a steady-state fixed bed reactor (FBR). Transesterification of palm stearin (PS) and waste cooking palm oil (WCPO) with ethanol in the presence of calcium oxide impregnated palm shell activated carbon (CaO/PSAC) solid catalyst was investigated. This work was determined the optimum conditions for the production of ethyl ester from PS and WCPO in order to obtain fatty acid ethyl ester (FAEE) with the highest yield. The effects of reaction variables such as residence time, ethanol/oil molar ratio, reaction temperature, catalyst bed height and reusability of catalyst in a reactor system on the yield of biodiesel were considered. The optimum conditions were the residence time 2-3 h, ethanol/oil molar ratio $16-20$, reaction temperature at $80^{\circ} \mathrm{C}$, and catalyst bed height $300 \mathrm{~mm}$ which yielded $89.46 \%$ and $83.32 \%$ of the PS and WCPO conversion, respectively. CaO/PSAC could be used repeatedly for 4 times without any activation treatment and no obvious activity loss was observed. It has potential for industrial application in the transesterification of triglyceride (TG). The fuel properties of biodiesel were determined.
\end{abstract}

Keywords: biodiesel, calcium oxide, ethyl ester, fixed bed reactor, palm shell activated carbon

\section{Introduction}

Environmental concerns and worries about a decline in petroleum production levels in the near future have led to a surge of interest in biofuel [1]. Biodiesel is a renewable and environmentally friendly energy that can be produced from a range of organic feedstock including fresh or waste vegetable oils, animal fats, algal oil and oilseed plants. It is also an important substitute for petroleum diesel. The resulting biodiesel is quite similar to conventional diesel fuel in terms of its main characteristics. It is biodegradable and does not contribute to global warming due to the closed carbon cycle [2]. Biodiesel is most commonly produced by transesterification of triglycerides with short chain alcohols like methanol and ethanol. The reaction can be catalyzed either chemically or enzymatically and can also be carried out without catalysts under supercritical conditions [3].

Nowadays, mainly of the commercial biodiesel comes from the transesterification of vegetable oil using a basic catalyst. But homogeneous catalysts have many problems and lead to a reduced yield of biodiesel. Hydrolysis and saponification are side reactions of transesterification. Resulting in the formation of soap which is hard and high cost to separate the catalyst from the product. A large amount of wastewater is produced in separating and cleaning the catalyst and the products [4]. Heterogeneous catalyst process which has become attractive recently is proposed to be an effective biodiesel production process. It has a simpler separation process compared to homogeneous catalyst process [5]. Solid-base catalysts have great potential for

\footnotetext{
* Corresponding author:

Email: achanai130@gmail.com
} 
biodiesel processing with reasonable reaction rates under mild conditions. Metal oxides, alumina-supported alkali elements/hydroxides, rehydrated hydrotalcites, anion exchange resin and alkali-exchanged zeolite were used to study biodiesel synthesis utilizing heterogeneous catalytic processes [6]. Calcium oxide $(\mathrm{CaO})$ is a candidate for the solid base catalyst from an economical point of view [7]. Among the available supports, activated carbon (AC) has proved to be a highly effective catalyst support in liquid and vapor phase reactions such as heterogeneous tranesterification reaction. Its high specific surface area, inert carbon skeleton and controllable pore structure allows catalyst to disperse over it largely and effectively. In addition, it is stable in high pressure and temperature reaction conditions [8].

Biodiesel production at a large scale is commonly accommodated in continuous stirred tank reactor (CSTR), because of the ease of construction, operation and maintenance. The disadvantage of the CSTR is that it can introduce mechanical damage to the solid catalyst, which can reduce the reusability of the heterogeneous catalyst and affect the economic feasibility of the processes. A fixed bed reactor (FBR) reduces the level of shear stress to catalyst particles and enables continuous operation. However, the FBR can be limited by a high pressure drop over the bed or obstruction of the catalyst bed by accumulation of insoluble components from the reaction mixture [9].

The methanolysis reactions are well-known because it has been used industrially for the past 50 years to simplify the manufacture of soaps and detergents. Methanol is highly toxic, can be absorbed through the skin, and is $100 \%$ miscible with water, so any kind of spill presents a serious problem. Ethanol, as an extraction solvent, is preferable to methanol because of its much higher dissolving power for oils. For this cause, ethanol is sometimes used as a suitable alcohol for the transesterification of vegetables oils. Producing ethyl esters rather than methyl esters is of considerable interest because it allows production of an entirelyagricultural fuel and the extra carbon brought about by the ethanol molecule slightly increases the heat content and the cetane number $[\mathbf{2}, \mathbf{1 0}]$.

In this study, we developed a FBR system for transesterification of triglyceride (TG). The work was focused on the reaction parameters that affected calcium oxide impregnated palm shell activated carbon (Ca0/PSAC) solid-catalyzed transesterification of palm stearin (PS) and waste cooking palm oil (WCPO) with ethanol in a continuously process. Our objectives were to better understand the relationships between the reaction variables (residence time, ethanol/oil molar ratio, reaction temperature, catalyst bed height and reusability) and the response, fatty acid ethyl ester (FAEE) yield (wt\%) and to achieve the optimal continuous transesterification condition in a FBR system.

\section{Experimental Method}

\subsection{Materials and reagents}

PS used in this study was obtained from Weerasuwan Co., Ltd. WCPO containing 40.98 wt\% FFA and $0.10 \mathrm{wt} \%$ water was collected in university cafeterias and local restaurants. The numerous fractions were blended in order to obtain waste oil. Non-oil components of the WCPO were removed by separation. Filter paper with an average pore size of $5 \mu \mathrm{m}$ was used to remove impurities from the oil feedstock before use. The basic properties of oil are shown in Table 1 . The AC (1-2 mm particle size) used in this work was palm shellbased, produced by physical and chemical activation process. All other chemicals were analytical grade reagents (Merck, $>99 \%$ purity) and were used as received.

Table 1

Physicochemical properties of PS and WCPO feedstock

\begin{tabular}{lcc}
\multicolumn{1}{c}{ Properties } & PS & WCPO \\
\hline Density, g/ $\mathrm{cm}^{3} @ 80^{\circ} \mathrm{C}$ & 0.861 & 0.868 \\
Relative molecular weight & 891.5 & 900.0 \\
Saponification value, mg KOH/g oil & 172.7 & 156.6 \\
Acid value, mg KOH/g oil & 0.40 & 97.03 \\
Free fatty acid (FFA) content, $\%$ & 0.20 & 40.98 \\
Water content, \% & 0.13 & 0.10 \\
Impurity, \% & No & 3.00 \\
\hline
\end{tabular}

\subsection{Catalyst preparation}

Heterogeneous catalyst was prepared according to the conventional incipient wetness impregnation (IWI) of aqueous solutions of the corresponding precursors on an AC support. Calcium nitrate salt $\left(\mathrm{Ca}\left(\mathrm{NO}_{3}\right)_{2} .4 \mathrm{H}_{2} \mathrm{O}\right)$ was completely dissolved in deionized water at room temperature. Amount of metal loading was maintained at $20 \mathrm{mmol} \mathrm{metal} / \mathrm{g}$ support. The support was then added into the solution followed by vigorous mixing. After mixture for $4 \mathrm{~h}$, the paste was dried in an oven at $120^{\circ} \mathrm{C}$ overnight. The dried solid was calcined in a horizontal automatic tubular furnace (Fig. 1) at $600^{\circ} \mathrm{C}$ for $4 \mathrm{~h}$ under nitrogen atmosphere. The characterization of $\mathrm{CaO} / \mathrm{PSAC}$ solid catalyst has been reported in our previous publication [11]. In sum, synthesized catalyst shows the potential applications to transesterification of TG.

\subsection{Catalytic reaction procedure}

The continuous transesterification was performed in a FBR (Fig. 2). The reactor was composed of a waterjacketed stainless steel column with an external diameter of $60 \mathrm{~mm}$ and a height of $345 \mathrm{~mm}$. The column was packed with $\mathrm{CaO} / \mathrm{PSAC}$ solid-base catalyst. TG and ethanol were charged into the system using two separate raw material pumps. The reactants were mixed and preheated in a mixing tank. 


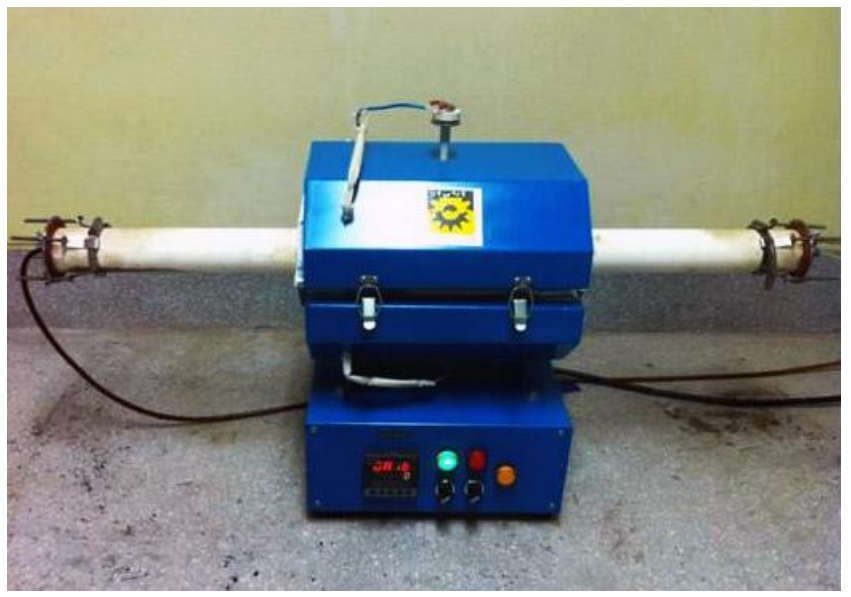

Fig. 1 Horizontal automatic tubular furnace for calcination

The mixture was fed to the inlet of reactor using a pump (1-4 $\mathrm{mL} / \mathrm{min}$ ). The reaction temperature was controlled by a heater to keep constant temperature with an error of $\pm 1.0^{\circ} \mathrm{C}$. The temperature difference between the inlet and the outlet was below $1.0{ }^{\circ} \mathrm{C}$ during all the runs. Temperature and pressure of the system were monitored by temperature indicator and pressure gauges. The sample obtained was purified by reduced pressure distillation to remove the excess methanol and water generated during reaction.

The continuous production of ethyl ester from ethanol and TG (PS and WCPO) was carried out in a FBR at atmospheric pressure. The effects of residence time
(1 to $4 \mathrm{~h}$ ), ethanol/oil molar ratio (12 to 28), reaction temperature $\left(70\right.$ to $\left.90^{\circ} \mathrm{C}\right)$, catalyst bed height $(150$ to $300 \mathrm{~mm}$ ) and reusability of catalyst (1 to 4 times) on the conversion to FAEE were studied. After a certain period of time, a known amount of sample was taken out from the reactor for analysis. All experiments were repeated 3 times and the standard deviation was never higher than $7 \%$ for any point.

\subsection{Analysis of ethyl ester}

Composition of the FAEE was analyzed with a gas chromatograph-mass spectrometry (GC-MS QP2010 Plus, Shimadzu Corporation, Japan) equipped with a flame ionization detector (FID) and a capillary column $30 \mathrm{~m} \times 0.32 \mathrm{~mm} \times 0.25 \mu \mathrm{m}$ (DB-WAX, Carbowax 20M). \%Yield of ethyl ester was calculated by Eq. (1):

$$
\% \text { Yield }=\frac{m_{I S} A_{E E}}{m_{E E} A_{I S}}
$$

Where mIS is the mass of internal standard added to the sample, AIS is the peak area of internal standard, $\mathrm{mEE}$ is the mass of the ethyl ester sample and AEE is the peak area of the ethyl ester sample [12].

The ethyl ester samples were then analyzed for fuel properties such as kinematic viscosity, density, flash point, cloud point, pour point, acid value and water content as per ASTM methods.

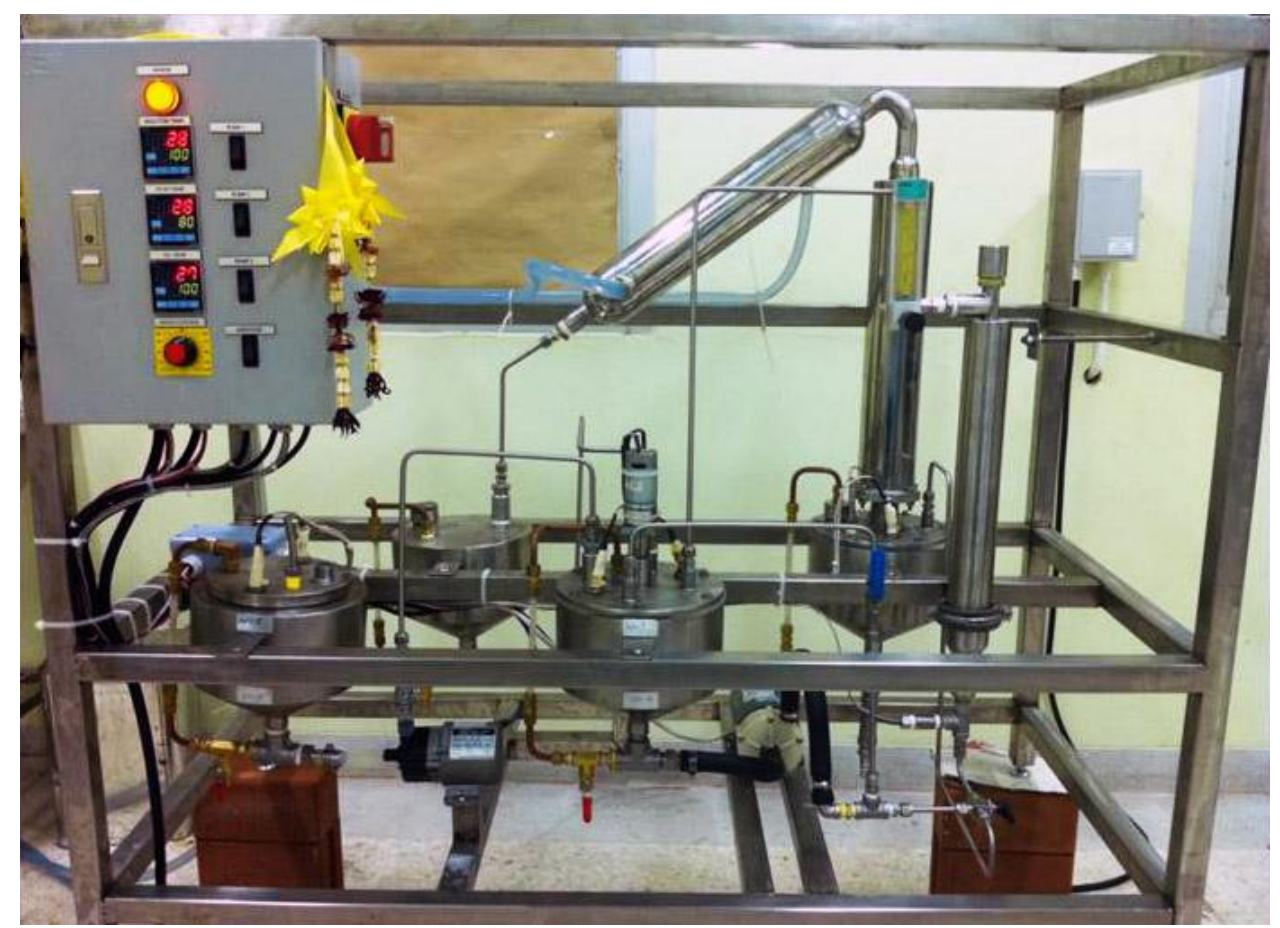

Fig. 2 Continuously process for transesterification and distillation 


\section{Results and Discussion}

\subsection{Process optimization for ethyl ester production}

In this study, the effect of residence time on the conversion of $\mathrm{TG}$ to ethyl ester was investigated. Residence time is one of the key parameters during the continuous transesterification carried out in the FBR. Changing the flow rate of feedstock chemical, different residence time was obtained [13]. The ethanol/oil molar ratio was kept 20 , reaction temperature of $80^{\circ} \mathrm{C}$, catalyst bed height of $300 \mathrm{~mm}$ and the pressure fixed at atmospheric pressure. Figure 3 shows the effect of residence time on the $\%$ yield of FAEE in our experiments. It was clear that the conversion increased with the residence time inside the FBR, and the higher the FFA content, the lower the conversion. In the initial stages of the transestherification reaction, production of ethyl esters was rapid, and the rate diminished and finally reached equilibrium [2] in about $2.0 \mathrm{~h}$ and $3.0 \mathrm{~h}$ for PS and WCPO, respectively. This can be explained by that transesterification reaction between $\mathrm{TG}$ and alcohol is reversible, when the residence time is long enough [14].

The excess of ethanol is necessary because it can increase the rate of ethanolysis. Normally, stoichiometric molar ratio of methanol to TG is near 6:1 when the alkali-catalyzed process is used. However, it increases to $30: 1$, even $50: 1$, in the acid-catalyzed one to ensure high conversion [15]. The effect of ethanol/oil molar ratio was investigated from 12 to 28. It is shown that the yield of ethyl ester rapidly increases with increasing molar ratio of ethanol/oil. The \%yield achieved $91.23 \%$ and $83.32 \%$ for PS and WCPO, respectively, in $3 \mathrm{~h}$ when the ratio of ethanol to TG was 20:1 (Fig. 4). Since biodiesel production by transesterification is a reversible reaction, the production yield could be elevated by introducing excess amount of the reactant ethanol to change the equilibrium. The more excess of ethanol was added, the higher conversion of TG to FAEE was achieved in the same residence time. However, when the ratio was over 20:1, the increment of conversion was small [10]. Therefore, the optimal molar ratio of ethanol/waste oil of 16 and 20 for PS and WCPO, respectively, are preferable.

In general, the reaction temperature can influence the reaction rate and ethyl ester yield. The transesterification of TG with ethanol to ethyl ester was carried out over the catalysts of $\mathrm{CaO} / \mathrm{PSAC}$ at reaction temperature $70-90^{\circ} \mathrm{C}$. The $\%$ yields of ethyl ester after 3 $\mathrm{h}$ of residence time are shown as a function of temperature in Figure 5. The yields of biodiesel were obviously rising from 73.83 to $89.46 \%$ for PS and 66.85 to $83.32 \%$ for WCPO with the increasing temperature from 70 to $80^{\circ} \mathrm{C}$. The effect of reaction temperature on promoting transesterification can be explained due to endothermic reaction [16]. The highest yield rate was obtained at the reaction temperature of $80^{\circ} \mathrm{C}$. When the reaction temperature continued to increase over $80^{\circ} \mathrm{C}$, the conversion was decreased. The reaction temperature consumedly exceeds the boiling point of ethanol such as 85 and $90^{\circ} \mathrm{C}$, and the ethanol will quickly vaporize and form a large number of bubbles, which inhibits the reaction on the two-phase interface [17]. Moreover, in order to save energy, it is necessary to choose the relative low temperature. Therefore, the optimum reaction temperature for the transesterification of TG to ethyl ester is considered to be around $80^{\circ} \mathrm{C}$.

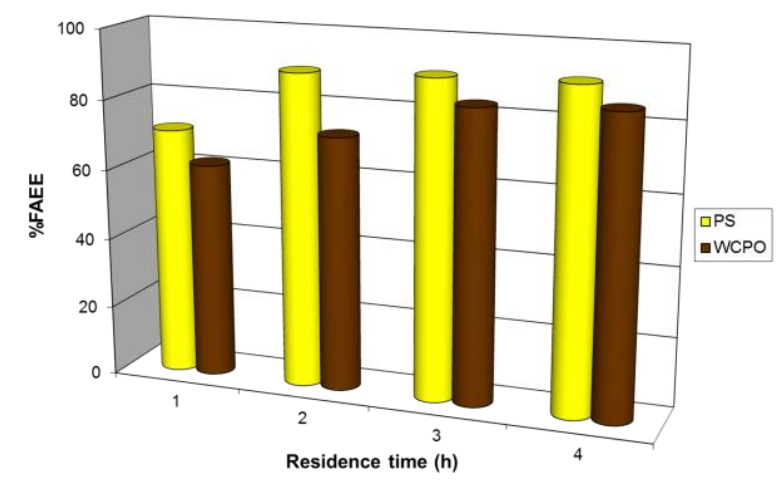

Fig. 3 Effect of residence time on \% yield of ethyl ester

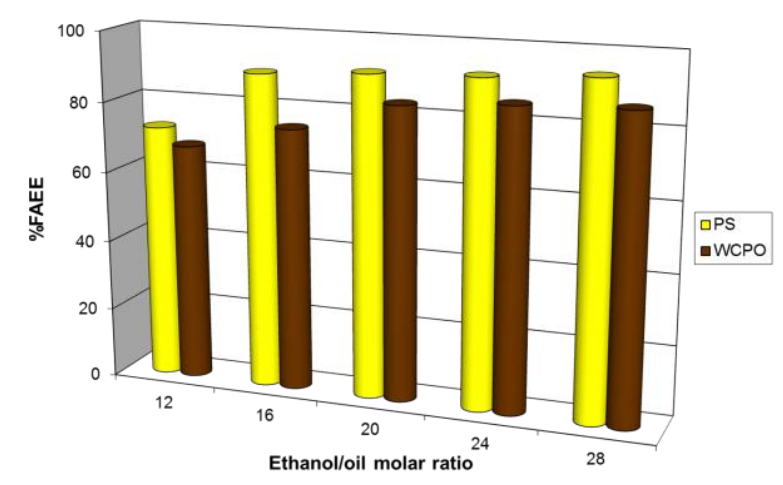

Fig. 4 Effect of ethanol/oil molar ratio on \% yield of ethyl ester

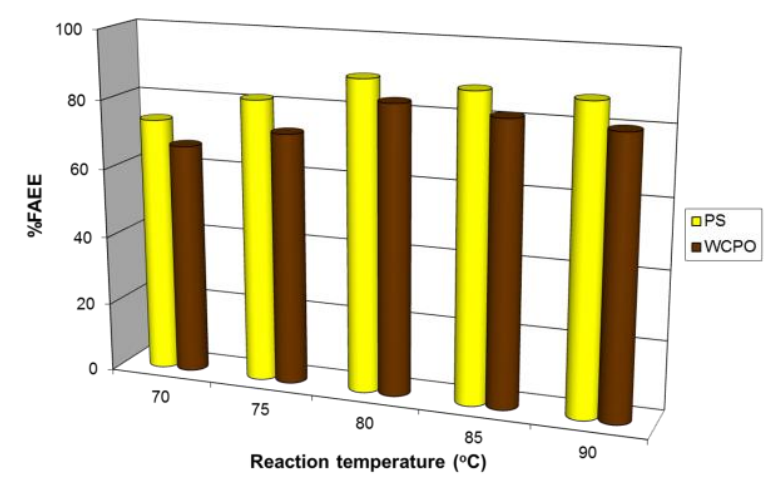

Fig. 5 Effect of reaction temperature on \% yield of ethyl ester 


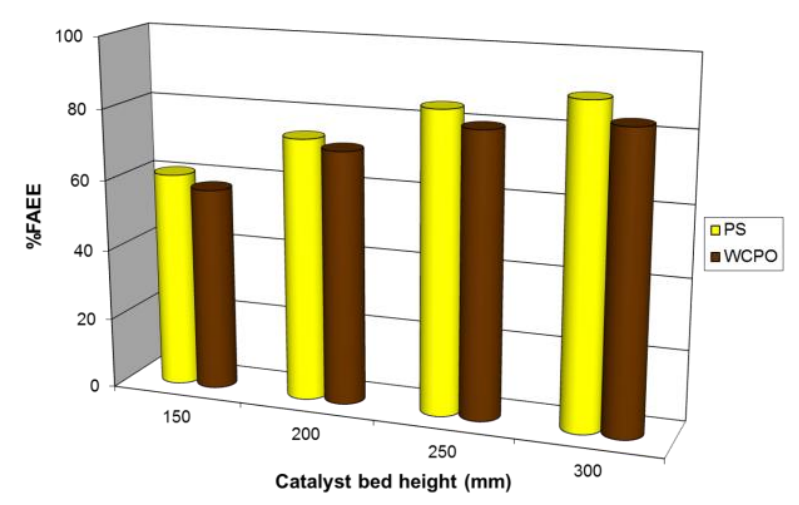

Fig. 6 Effect of catalyst bed height on \% yield of ethyl ester

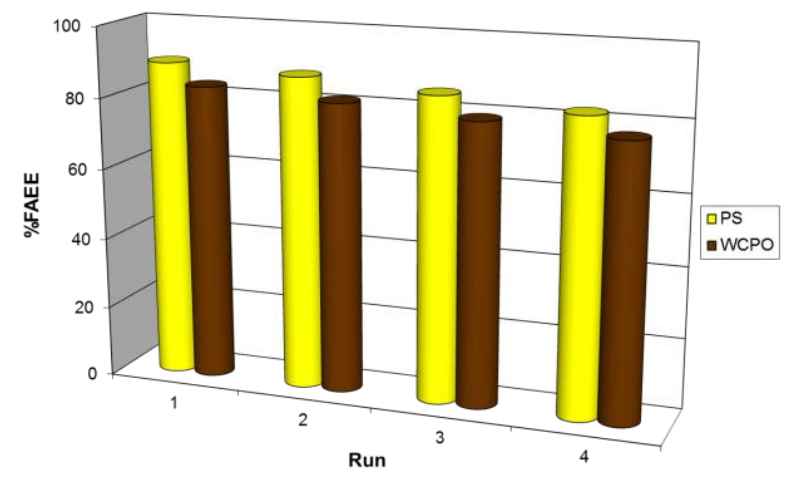

Fig. 7 Effect of reusability of catalyst on \% yield of ethyl ester

As shown in Figure 6, the yield of biodiesel was greatly dependent on the amount of catalyst applied. The FAEE content increased along with the increase in catalyst bed height, because the more catalyst available, the more molecules were absorbed onto the active center of the catalyst [18]. The yield increased rapidly from $60.92 \%$ to $89.46 \%$ for PS and $57.45 \%$ to $83.32 \%$ for WCPO with the increase of the catalyst bed height from 150 to $300 \mathrm{~mm}$. It demonstrates that a high catalyst bed height provides a longer residence time and more active sites to promote the reaction between TG and ethanol at a given flow rate [13]. However, when the catalyst bed height exceeded $250 \mathrm{~mm}$, the rate of reaction increased slightly. Therefore, the optimum catalyst bed height for biodiesel production in this research is found to be $250 \mathrm{~mm}$.

Reusability of the CaO/PSAC catalysts was evaluated in the trans-esterification, and the results are shown in Figure 7. The used catalyst was collected after the reaction and reused for the next reaction test without pretreatment or regenerating. The results indicated that the catalyst could be reusable at least 4 times with a 7.51-7.60\% FAEE drop from the $89.46 \%$ and $83.32 \%$ FAME for PS and WCPO, respectively, obtained over fresh catalyst. It turned out that the used catalyst has still maintained the characteristic $\mathrm{CaO}$ phase after being reused 4 times. As a result, the heterogeneous catalyst exhibited a high potential to be used for catalyzing biodiesel production in heterogeneous process with good reusability [19].

\subsection{Fuel properties of ethyl ester}

The fuel properties of ethyl ester obtained in this work are summarized in Table 2 . It can be seen that most of its properties are in the range of fuel properties as described in the latest standards for biodiesel $[8, \mathbf{1 0}]$.

Table 2

The fuel properties of ethyl ester derived from PS and WCPO

\begin{tabular}{lcc}
\hline \multicolumn{1}{c}{ Properties } & PS & WCPO \\
\hline Kinematic viscosity, $\mathrm{mm}^{2} / \mathrm{s} @ 40{ }^{\circ} \mathrm{C}$ & 4.7 & 4.8 \\
Density, g/ $\mathrm{cm}^{3} @ 80{ }^{\circ} \mathrm{C}$ & 0.878 & 0.876 \\
Flash point, ${ }^{\circ} \mathrm{C}$ & 166 & 167 \\
Cloud point, ${ }^{\circ} \mathrm{C}$ & 11 & 12 \\
Pour point, ${ }^{\circ} \mathrm{C}$ & 6 & 8 \\
Acid value, $\mathrm{mg} \mathrm{KOH} / \mathrm{g}$ oil & 0.44 & 0.98 \\
Water content, $\%$ & 0.02 & 0.03 \\
\hline
\end{tabular}

\section{Conclusions}

This research was carried out to determine optimum conditions for the production of ethyl ester from PS and WCPO in order to obtain FAEE with the highest yield. CaO/PSAC catalyst was also successfully tested in the transesterification reaction of TG. The optimum conditions, which yielded a conversion of PS and WCPO of nearly $89 \%$ and $83 \%$, were residence time 2-3 h, ethanol/oil molar ratio 16-20, reaction temperature $80^{\circ} \mathrm{C}$ and catalyst bed height $300 \mathrm{~mm}$ with pressure $1 \mathrm{~atm}$ in FBR. The experimental results show that $\mathrm{CaO} / \mathrm{PSAC}$ had excellent activity and stability during transesterification. The catalyst was used for 4 times and no apparent activity loss was observed. The fuel properties of the biodiesel so obtained meet all biodiesel standards. As a solid catalyst, $\mathrm{CaO} / \mathrm{PSAC}$ can decrease the cost of biodiesel and the steps of purification. It has potential for industrial application in the transesterification of TG to FAEE.

\section{Acknowledgement}

This work is supported by Silpakorn University Research and Development Institute (SURDI 52/02/06.01-53/02/04.01). The authors acknowledge sincerely the Department of Materials Science and Engineering (MSE), Faculty of Engineering and Industrial Technology, Silpakorn University (SU) and National Center of Excellence for Petroleum, Petrochemicals, and Advanced Materials (PPAM), Chulalongkorn University (CU) for supporting and encouraging this investigation. 


\section{References}

[1] Vasudevan PT, Briggs M (2008) Biodiesel Production-Current State of the Art and Challenges. Journal of Industrial Microbiology and Biotechnology 35: 421-430.

[2] Santana A, Maçaira J, Larrayoz MA (2012) Continuous Production of Biodiesel Using Supercritical Fluids: A Comparative Study Between Methanol and Ethanol. Fuel Processing Technology 102: 110-115.

[3] Salum TFC, Villeneuve P, Barea B, Yamamoto CI, Côcco LC, Mitchell DA, Krieger N (2010) Synthesis of Biodiesel in Column Fixed-Bed Bioreactor Using the Fermented Solid Produced by Burkholderia Cepacia LTEB11. Process Biochemistry 45: 13481354.

[4] Noiroj K, Intarapong P, Luengnaruemitchai A, Jai-In S (2009) A Comparative Study of $\mathrm{KOH} / \mathrm{Al} 2 \mathrm{O} 3$ and $\mathrm{KOH} / \mathrm{NaY}$ Catalysts for Biodiesel Production via Transesterification from Palm Oil. Renewable Energy 34: 1145-1150.

[5] Hameed BH, Goh CS, Chin LH (2009) Process Optimization for Methyl Ester Production from Waste Cooking Oil Using Activated Carbon Supported Potassium Fluoride. Fuel Processing Technology 90: 1532-1537.

[6] Hsieh LS, Kumar U, Wu JCS (2010) Continuous Production of Biodiesel in a Packed-Bed Reactor Using Shell-Core Structural $\mathrm{Ca}(\mathrm{C} 3 \mathrm{H} 703) 2 / \mathrm{CaCO} 3$ Catalyst. Chemical Engineering Journal 158: 250-256.

[7] Kouzu M, Hidaka JS (2012) Transesterification of Vegetable Oil into Biodiesel Catalyzed by CaO: A Review. Fuel 93: 1-12.

[8] Buasri A, Ksapabutr B, Panapoy M, Chaiyut N (2012) Biodiese Production from Waste Cooking Palm Oil Using Calcium Oxide Supported on Activated Carbon as Catalyst in a Fixed Bed Reactor. Korean Journal Chemical Engineering 29: DOI:10.1007/s11814-012-0047-7 (in press).

[9] Xu Y, Nordblad M, Woodley JM (2012) A Two-Stage Enzymatic Ethanol-Based Biodiesel Production in a Packed Bed Reactor.
Journal of Biotechnology:

http://dx.doi.org/10.1016/j.jbiotec.2012.05.017 (in press).

[10] Buasri A, Chaiyut N, Ketlekha P, Mongkolwatee W, Boonrawd S (2009) Biodiesel Production from Crude Palm Oil with a High Content of Free Fatty Acids and Fuel Properties. Chiang Mai University Journal of Natural Sciences 8: 115-124.

[11] Buasri A, Chaiyut N, Nakweang C (2011) Preparing Activated Carbon from Palm Shell for Biodiesel Fuel Production. Chiang Mai Journal of Science 38: 572-578.

[12] Jiang ST, Zhang FJ, Pan LJ (2010) Sodium Phosphate as a Solid Catalyst for Biodiesel Preparation. Brazilian Journal of Chemical Engineering 27: 137-144.

[13] Feng Y, Zhang A, Li J, He B (2011) A Continuous Process for Biodiesel Production in a Fixed Bed Reactor Packed with CationExchange Resin as Heterogeneous Catalyst. Bioresource Technology 102: 3607-3609.

[14] Lu P, Yuan Z, Li L, Wang Z, Luo W (2010) Biodiesel from Different Oil Using Fixed-Bed and Plug-Flow reactors. Renewable Energy 35: 283-287.

[15] Zhang Y, Dubé MA, McLean DD, Kates M (2003) Biodiesel Production from Waste Cooking Oil: 1. Process Design and Technological Assessment. Bioresource Technology 89: 1-16.

[16] Samart C, Sreetongkittikul P, Sookman C (2009) Heterogeneous Catalysis of Transesterification of Soybean Oil Using KI/Mesoporous Silica. Fuel Processing Technology 90: 922-925.

[17] Long T, Deng Y, Gan S, Chen J (2010) Application of Choline Chloride $\bullet \mathrm{XZnCl} 2$ Ionic Liquids for Preparation of Biodiesel. Chinese Journal of Chemical Engineering 18: 322-327.

[18] Chen Y, Xiao B, Chang J, Fu Y, Lv P, Wang X (2009) Synthesis of Biodiesel from Waste Cooking Oil Using Immobilized Lipase in Fixed Bed Reactor. Energy Conversion and Management 50: 668673.

[19] Khemthong $P$, Luadthong C, Nualpaeng W, Changsuwan P, Tongprem P, Viriya-empikul N, Faungnawakij K (2012) Industrial Eggshell Wastes as the Heterogeneous Catalysts for Microwave-Assisted Biodiesel Production. Catalysis Today: DOI:10.1016/j.cattod.2011.12.024 (in press). 